\title{
Telemedicine and COVID-19: an Observational Study of Rapid Scale Up in a US Academic Medical System
}

$\mathrm{J}$ Gen Intern Med 35(9):2823-5

DOI: $10.1007 / \mathrm{s} 11606-020-05917-9$

(c) Society of General Internal Medicine 2020

\section{INTRODUCTION}

The COVID-19 pandemic has challenged health systems in many ways. One positive change may be a dramatic increase in telemedicine use. Health care systems have been moving to provide virtual care for some time, but progress has been slow. ${ }^{1-4}$ We describe how, in a large academic medical system with a high case mix index and diverse racial profile, we dramatically scaled up our slowly growing telemedicine program within a few weeks. We provide information on lessons learnt and patient experience.

\section{METHODS}

We define telemedicine here as synchronous live consultation via video. Keck Medicine of USC, which provides mainly tertiary and quaternary care for East Los Angeles and Southern California, began phased implementation of telemedicine in 2018, aiming for 20 clinics by 2019 .

With the COVID-19 outbreak, we rapidly scaled up. Declaration of a state of emergency relaxed credentialing guidelines and allowed use of other video-capable platforms in addition to our usual platform, InTouch. ${ }^{5}$ Telemedicine privileges were granted to all physicians and providers for one year. Each clinic determined their own workflows and received an onboarding packet comprising a training video, guidance for coding and documentation, consenting and prescribing principles, and job aids. Providers had access to a testing site for practice and were offered one-on-one training. The telemedicine implementation team augmented training staff from two to eleven. A command center was established to coordinate workflows and to allow a drop-in point for advice or rapid training.

\section{RESULTS}

By mid-2019, we had activated fewer than 15 clinics and delivered less than 400 televisits. By end of March 2020, we

Received April 14, 2020

Accepted May 6, 2020

Published online June 4, 2020 operated 110 virtual clinics, completed more than 2000 visits (Fig. 1), and trained 523 new staff.

Results of a patient satisfaction questionnaire from over 470 patients surveyed during the scale up period are shown in Table 1. Many patients included positive comments on avoiding travel, parking, and the risks of attending a clinic, a few patients expressed concern that the visit was charged at the same rate as an in-person visit, and that they missed the physical examination.

\section{DISCUSSION}

The novel coronavirus epidemic provided a critical stimulus to transform our telemedicine program in just a few weeks. Challenges created by such a sudden expansion included the need to deliver training remotely and learn a new web-based platform while simultaneously delivering patient care. Providing live coaching and the ability to run test scenarios proved helpful for troubleshooting, and jumpstarted rapid implementation across ambulatory services.

To meet demand, switching to other platforms such as Zoom from HIPAA compliant platforms, although allowed within relaxed CMS regulations, ${ }^{5}$ caused concerns about privacy. ${ }^{1,2}$

Before the COVID-19 pandemic, barriers to widespread usage of telemedicine for most health systems included billing, reimbursement, credentialing, and choosing an effective delivery platform. ${ }^{1-4}$ A common concern voiced was about the ability of some patients, particular the elderly and underserved, to manage technology., 6 The challenge of protecting patients and providers from COVID-19, along with regulatory and payment reform, has shown that rapid transition to virtual practice can occur. The majority of our patients managed to use the platform and were very satisfied with virtual visits. Reduced wait times for patients and more effective use of time for providers were noted. Some patients were left feeling wanting, expecting a physical examination and waiver of the co-pay fee.

The limitation of this short report is that it is only the experience of one health system. However, media reports and discussions with colleagues suggest that our experience is echoed worldwide. There are questions to be answered after the pandemic, such as how to manage the inability to do a physical examination and how do we best use evolving monitoring technology? However, there are 
a

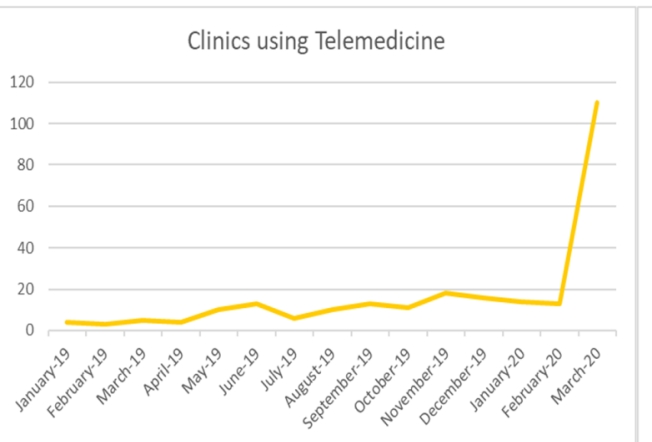

b

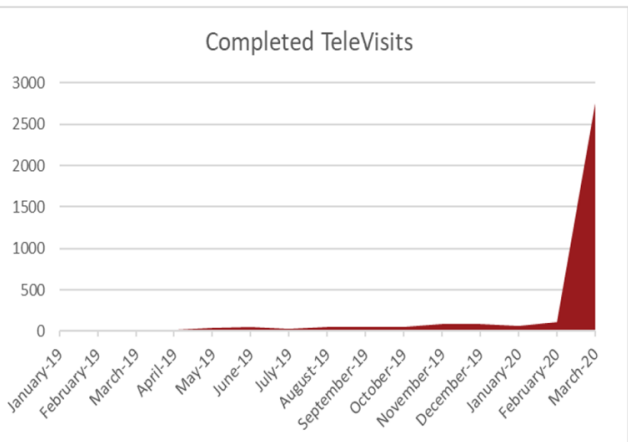

Fig. 1 Data showing the dramatic increase in both the number of clinics a providing telemedicine and $b$ the number of completed TeleVisits. The latter number only represents completed visits on our InTouch platform-visits completed on Zoom or Face Time are not included, and so the actual increase in visits is even greater. The dramatic increase mainly occurred after the "stay at home" order for California on March 19, 2020.

some real advantages to virtual care, over and above reducing travel, we can see the patients' home and get some idea of how they live. Forgotten medications can be produced and we can see bottles and packages.

We may have to change behavior for some time until a vaccine is available against COVID-19. Protecting older patients and those with chronic illnesses from exposure will remain a priority. However, it seems likely that the rapid

Table 1 Patients were asked to complete a brief online survey at the end of each virtual visit to assess the quality of care.

Responses shown to the questionnaire are from over 470 patients who responded to a survey during the ramp-up period from January 1, 2020, to March 26, 2020. The response rate was between 22 and $24 \%$

\begin{tabular}{|c|c|c|c|}
\hline Survey question & $\begin{array}{l}\text { Favorable } \\
(N, \%)\end{array}$ & $\begin{array}{l}\text { Neutral } \\
(N, \%)\end{array}$ & $\begin{array}{l}\text { Unfavorable } \\
(N, \%)\end{array}$ \\
\hline $\begin{array}{l}\text { I would recommend } \\
\text { virtual visits to friends } \\
\text { \& family }\end{array}$ & $374(83 \%)$ & $53(12 \%)$ & $26(6 \%)$ \\
\hline $\begin{array}{l}\text { I would like to use } \\
\text { virtual visits for other } \\
\text { types of care }\end{array}$ & $354(77 \%)$ & $75(16 \%)$ & $31(7 \%)$ \\
\hline $\begin{array}{l}\text { Instructions for gaining } \\
\text { access to the system } \\
\text { and completing my } \\
\text { visit were clear and } \\
\text { easy to complete }\end{array}$ & $384(82 \%)$ & $42(9 \%)$ & $41(9 \%)$ \\
\hline $\begin{array}{l}\text { My need \& } \\
\text { expectations for } \\
\text { standards of care were } \\
\text { met by having this visit } \\
\text { online }\end{array}$ & $408(86 \%)$ & $368 \%)$ & $32(7 \%)$ \\
\hline $\begin{array}{l}\text { The audio \& video } \\
\text { quality was appropriate } \\
\text { for clear } \\
\text { communication }\end{array}$ & $369(74 \%)$ & $43(9 \%)$ & $84(17 \%)$ \\
\hline
\end{tabular}

transformation in health care delivery that has occurred will remain long after the virus has gone.

Acknowledgments: Contributors: Michael Hochman MD for reviewing the manuscript, and Laura Paoletti and the TeleCARE team at Keck Medicine of USC for the data.

Carol J. Peden, $\mathrm{MD}^{1}$

Sirisha Mohan, $\mathrm{MD}^{2}$

Veronica Pagán, $M P H^{1}$

${ }^{1}$ Gehr Family Center for Health Systems Science and Innovation, Keck School of Medicine, University of Southern California,

Los Angeles, CA, USA

${ }^{2}$ Department of Family Medicine, Keck School of Medicine, University of Southern California, Los Angeles, CA, USA

Corresponding Author: Carol J. Peden, MD; Gehr Family Center for Health Systems Science and Innovation, Keck School of Medicine, University of Southern California Los Angeles, CA, USA (e-mail: carol.peden@med.usc.edu).

\section{Compliance with Ethical Standards:}

Conflict of Interest: The authors declare they have no conflicts of interest and have completed the appropriate ICMJE forms on disclosure of conflicts of interest stating that.

\section{REFERENCES}

1. Kruse CS, Karem P Hofflet $\mathbf{K}$, Vegi L, Ravi K, Brooks M. Evaluating barriers to adopting telemedicine worldwide: A systematic review. J Telemed Telecare. 2018;24(1):4-12.

2. Public Health Institute for Connected Health Policy. Telehealth Policy Barriers 2019. https://www.telehealthpolicy.us/sites/default/files/201902/TELEHEALTH\%20POLICY\%2OBARRIERS\%202019\%20FINAL.pdf. Acessed April $8^{\text {th }} 2020$. 
3. American College of Obstetrics and Gynecology. ACOG Committee Opinion Summary 798. Implementing Telehealth in Practice. Obstet Gynecol. 2020;135(2):493-494.

4. Martinez KA, Rood M, Jhangiani N, et al. Patterns of Use and Correlates of Patient Satisfaction with a Large Nationwide Direct to Consumer Telemedicine Service. J Gen Intern Med. 2018;33:1768-1773. https:// doi.org/10.1007/s11606-018-4621-5.

5. CMS: Medicare Telemedicine Health Care Provider Fact Sheet. March $17^{\text {th }}$ 2020. https://www.cms.gov/newsroom/fact-sheets/medicare-telemedicine-health-care-provider-fact-sheet. Accessed March $8^{\text {th }} 2020$.
6. Peden CJ, Saxon L. Digital Technology to Engage Patients: Ensuring Access for All. NEJM Catalyst Innovations in Care Delivery. https://catalyst.nejm. org/doi/full/10.1056/CAT.17.0376. Accessed April $8^{\text {th }} 2020$.

Publisher's Note: Springer Nature remains neutral with regard to jurisdictional claims in published maps and institutional affiliations. 